\title{
Development of a scalable weight loss intervention for low-income workers through adaptation of interactive obesity treatment approach (iOTA)
}

Rachel G. Tabak ${ }^{1 *}$ (D) Jaime R. Strickland ${ }^{2}$, Richard I. Stein ${ }^{3}$, Hank Dart ${ }^{4}$, Graham A. Colditz ${ }^{4}$, Bridget Kirk ${ }^{2}$, Ann Marie Dale ${ }^{2}$ and Bradley A. Evanoff ${ }^{2}$

\begin{abstract}
Background: Describing how and why an evidence-based intervention is adapted for a new population and setting using a formal evaluation and an adaptation framework can inform others seeking to modify evidence-based weight management interventions for different populations or settings. The Working for You intervention was adapted, to fit a workplace environment, from Be Fit Be Well, an evidence-based intervention that targets weight-control and hypertension in patients at an outpatient clinic. Workplace-based efforts that promote diet and activity behavior change among low-income employees have potential to address the obesity epidemic. This paper aims to explicitly describe how Be Fit Be Well was adapted for this new setting and population.
\end{abstract}

Methods: To describe and understand the worksite culture, environment, and policies that support or constrain healthy eating and activity in the target population, we used qualitative and quantitative methods including key informant interviews, focus groups, and a worker survey; these data informed intervention adaptation. We organized the adaptations made to Be Fit Be Well using an adaptation framework from implementation science.

Results: The adapted intervention, Working for You, maintains the theoretical premise and evidence-base underpinning Be Fit Be Well. However, it was modified in terms of the means of delivery (i.e., rather than using interactive voice response, Working for You employs automated SMS text messaging), defined as a modification to context by the adaptation framework. The adaptation framework also includes modifications to content; in this case the behavioral goals were modified for the target population based on updated science related to weight loss and to target a workplace population (e.g., a goal to avoiding free food at work).

Conclusions: If effective, this scalable and relatively inexpensive intervention can be translated to other work settings to reduce obesity and diabetes risk among low-SES workers, a group with a higher prevalence of these conditions. Using a formal evaluation and framework to guide and organize how and why an evidence-based intervention is adapted for a new population and setting can push the field of intervention research forward.

Trial registration: ClinicalTrials.gov: NCT02934113; Received: October 12, 2016; Updated: November 7, 2017.

Keywords: Worksite intervention, Weight loss, Implementation science, Adaptation

\footnotetext{
* Correspondence: rtabak@wustl.edu

${ }^{1}$ Prevention Research Center in St. Louis, The Brown School, Washington

University in St. Louis, 1 Brookings Dr, St. Louis, MO 63130, USA

Full list of author information is available at the end of the article
}

(c) The Author(s). 2018 Open Access This article is distributed under the terms of the Creative Commons Attribution 4.0 International License (http://creativecommons.org/licenses/by/4.0/), which permits unrestricted use, distribution, and reproduction in any medium, provided you give appropriate credit to the original author(s) and the source, provide a link to the Creative Commons license, and indicate if changes were made. The Creative Commons Public Domain Dedication waiver (http://creativecommons.org/publicdomain/zero/1.0/) applies to the data made available in this article, unless otherwise stated. 


\section{Background}

The current epidemic of obesity in the US and other countries is projected to greatly increase the prevalence of diabetes and other health consequences [1-6]. Obesity is most prevalent among socioeconomically disadvantaged populations, including racial and ethnic minorities [7, 8]. National data show that obesity is strongly associated with low socioeconomic status (SES), which includes those in hourly and working-class jobs and employees with low education [9-14]. SES factors are related to environmental characteristics and risk behaviors that promote obesity, as well as limited access to weight management resources [15-19]. Despite the compelling evidence for the importance of healthy weight, few weight loss interventions have been rigorously tested in low-SES populations [20-22]. Adaptation of existing intervention models is needed to improve reach and sustainability while maintaining the effectiveness shown in interventions such as the Diabetes Prevention Program (DPP) [23].

Worksites are targeted as a priority location for health intervention efforts by employers, the Centers for Disease Control (CDC), and the National Institutes of Health (NIH) [24-29], because they offer an efficient and effective means of delivering and evaluating such programs, and offer opportunities to reach socially disadvantaged groups. Worksites offer ready access to populations, natural structures for social support, and the opportunity to build health promotion activities on existing communication networks. Importantly, there has been minimal evaluation of the effectiveness of worksite-based health promotion among low-SES employees [30, 31], a population with more limited access to and participation in worksite wellness programs [30, 32-41]. This may be attributable to a number of barriers such as stress and limited communication to these groups [24, 35, 38, 42-47], particularly for low-wage hospital employees [48, 49].

One program that successful promoted weight loss in a low-income, racially diverse population, Be Fit Be Well $(\mathrm{BFBW})$, was implemented in individuals with obesity and hypertension who received healthcare through community health centers $[50,51]$. This lifestyle modification program targeted multiple levels, included dietary messaging around the Dietary Approaches to Stop Hypertension (DASH) diet, and incorporated electronic as well as interpersonal supports; participants received both types of supports. Depending on the participant's available computer access and comfort with computer use, the electronic supports were delivered either through a Web-based system or through a telephone-based system using Interactive Voice Recognition; the electronic support component did not include personal contact. The interpersonal supports included community health workers and linkages to local resources. Behavioral targets for BFBW included diet, physical activity, and hypertension medication adherence, and outcomes assessed were weight loss, blood pressure control, and quality of life [52]. Overall, BFBW showed significant benefit for weight loss at 24 months [51].

While evidence-based interventions promoting weight loss and chronic disease prevention, such as BFBW, are readily available, they require adaptation for implementation in more diverse settings such as worksite settings with low-SES employee populations. Describing the process of adaptation is critical to advancing implementation science [53-56]. The application of a formal framework to an intervention and its use in another setting can advance implementation efforts by shedding light on the steps taken and the modifications required. This can help important stakeholders (e.g., other investigators, practitioners) understand why and how an intervention being implemented is different from the original intervention, and how they might further adapt the intervention for other settings and populations. For the current study, the BFBW program was adapted to fit a worksite intervention targeted at low-SES employees. This manuscript aims to use the model developed by Stirman et al. [55-57] to describe in detail the adaptation and process for adapting BFBW to enhance the external validity and transparency of the adapted intervention, Working for You (WFY) [55].

\section{Methods}

To put the adaptations made to BFBW in context, and inform others seeking to modify evidence-based weight management interventions for new contexts and populations, we used the adaptation framework developed by Stirman et al. [55-57] This framework was selected as it is recommended by Chambers et al. [54] as a method to capture adaptations to a specific evidence-based intervention. This framework was developed based on a review of articles describing modifications to evidence-based practices across a variety of interventions and settings [55, 57]. The most relevant components of the framework are summarized in Fig. 1, and these include four Contextual modifications (e.g., change in setting or format), three Content modifications (e.g., adding or omitting components), six levels at which modifications could occur (e.g., consistently throughout a system or organization or only for particular clients), and a code for modifications to Training or evaluation processes. Content modifications can be made at multiple levels.

We first assessed differences in the population and social setting that could affect the success of WFY so that modifications could be made accordingly. This includes changes in motivation for and barriers to engagement and sustainability. Exploratory, iterative, qualitative and quantitative methods including key informant interviews, focus groups, and a worker survey were used to describe and understand the worksite culture, environment, and 


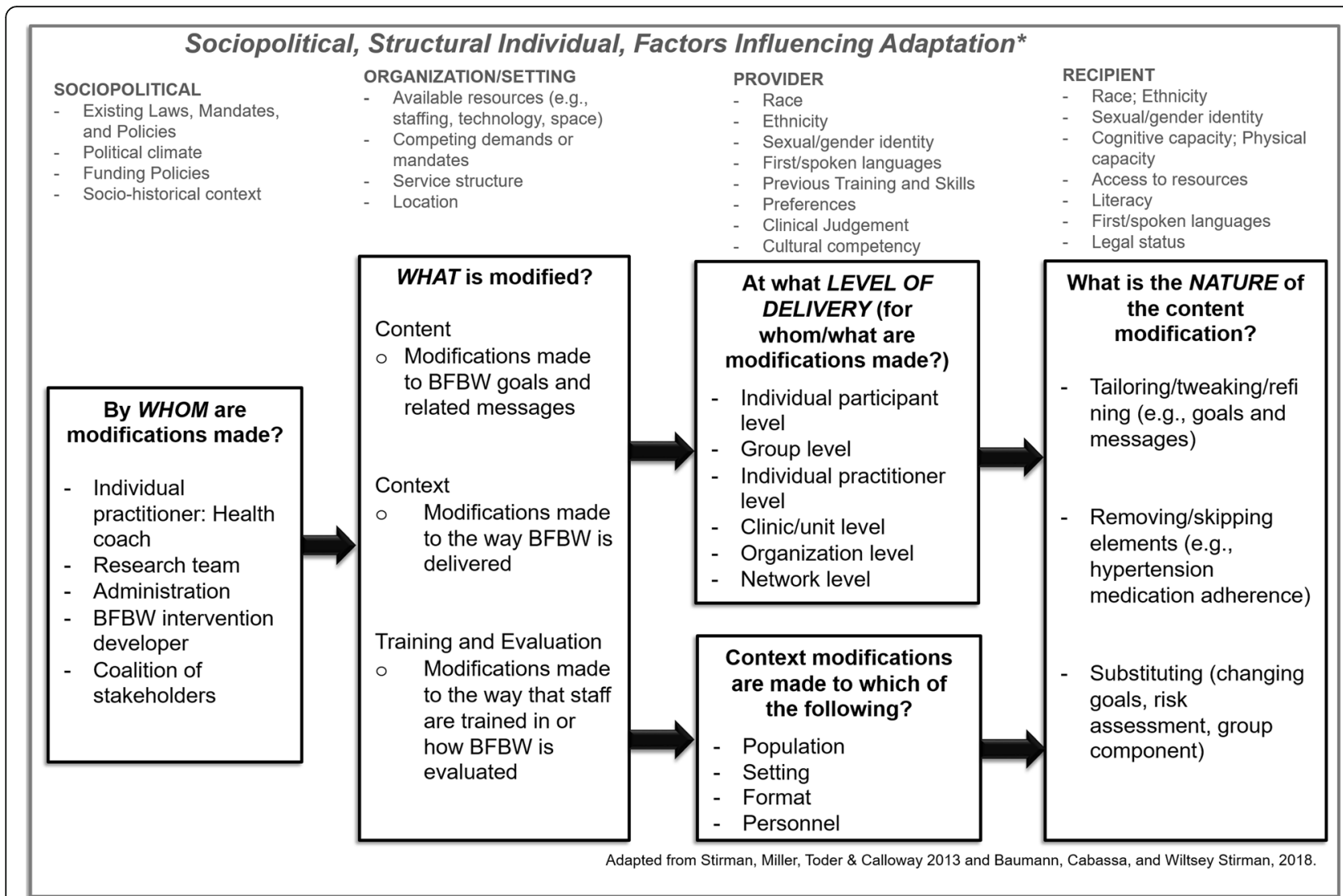

Fig. 1 Framework guiding intervention adaptation

policies that support or constrain healthy eating and physical activity in the target population (Table 1) [48, 49]. For all of these study components, our target audience was low-wage and hourly workers; therefore, in order to reach these groups, we recruited within specific hospital departments including housekeeping, food service, registration, and patient transport. We distributed flyers and sent emails to recruit focus group participants and worked with department managers to distribute surveys to employees. We interviewed some of those managers as well as members of the corporate wellness committee. All interviews and focus groups were conducted by experienced research team members.

First, we identified targets for modifying BFBW using surveys with 219 hospital workers (e.g., housekeepers, food service workers). The full survey methods and results have been published elsewhere [49]. Briefly, the survey found that workers with irregular schedules were less likely to participate in a worksite health promotion program [49]. These findings were incorporated into the content and context modifications described below, such as the inclusion of SMS text messaging and a workgroup-level intervention. Next, key informant interviews with five staff, including managers and wellness committee members, knowledge and expertise from the interdisciplinary team (described below), and a first round of 4 focus groups with 20 individuals (Focus Groups 1) were used to dive deeper into the modification targets, such as time and/or priority barriers to participation in the workplace programs offered [48]. We recruited a similar sample to that described for the survey; the methods and results for this qualitative work have been described elsewhere [48]. Briefly, experienced research team members used a semi-structured script to guide focus group discussions, which were audio recorded and transcribed. The full list of interview topics are published elsewhere [48], but include: work schedule, healthy eating priority, eating at work, current wellness programs. NVivo 10 software (QSR International Pty Ltd., Melbourne, Australia), was used to analyze transcriptions. Using a phenomenological approach, to find the "essence" or common themes across individual experiences [58], the thematic analysis aimed to answer: 1) "what impacts healthy eating and physical activity" and 2) "what can be modified at the workplace?", and codes were merged and grouped under main themes [48]. We conducted an additional set of four focus groups to gauge interest and willingness to participate in a text-messaging weight loss program and test preliminary versions of the messages 
Table 1 Summary of formative work to inform intervention adaptation

\begin{tabular}{|c|c|c|c|}
\hline Method & Participants & Topic & Key Findings \\
\hline Survey [49] & $\begin{array}{l}\text { Housekeepers, food service workers, patient } \\
\text { care technicians, registration clerks, medical } \\
\text { records clerks, and Emergency Medical } \\
\text { Services (EMS) workers } \\
N=219\end{array}$ & $\begin{array}{l}\text { Diet, physical activity, general health, } \\
\text { health-related work productivity, } \\
\text { commuting, work schedule, work culture } \\
\text { and organization, hours worked, dietary } \\
\text { history, attitudes toward behavior change, } \\
\text { effects of work environment on eating and } \\
\text { exercise habits, and current participation in } \\
\text { workplace programs }\end{array}$ & $\begin{array}{l}\text { Among this population, } 47 \% \text { had BMI } \\
\text { (Body Mass Index) }>30 ; 64 \% \text { report } \\
\text { trying to lose weight; } 27 \% \text { report } 20+ \\
\text { minutes of vigorous exercise more than } \\
2 \text { days per week; } 62 \% \text { sometimes or } \\
\text { often drink more than } 16 \text { oz of sugary } \\
\text { drinks a day. }\end{array}$ \\
\hline $\begin{array}{l}\text { Key informant } \\
\text { interview [48] }\end{array}$ & $\begin{array}{l}\text { Human resource managers and wellness } \\
\text { committee members } \\
N=5\end{array}$ & $\begin{array}{l}\text { Barriers and facilitators to implementing } \\
\text { wellness initiatives }\end{array}$ & $\begin{array}{l}\text { Communication difficulties are a major } \\
\text { barrier to implementing wellness efforts } \\
\text { (e.g., many workers were unaware of } \\
\text { the wellness initiatives offered by their } \\
\text { employer). }\end{array}$ \\
\hline $\begin{array}{l}\text { Focus groups } 1 \\
\text { [48] }\end{array}$ & $\begin{array}{l}\text { Housekeepers, patient care technicians, } \\
\text { unit secretaries } \\
N=4 \text { groups; } 20 \text { individuals }\end{array}$ & $\begin{array}{l}\text { Barriers and facilitators to participation in } \\
\text { wellness initiatives, healthy eating, and } \\
\text { physical activity }\end{array}$ & $\begin{array}{l}\text { Communication barriers to participation } \\
\text { and healthy eating: night-shift workers } \\
\text { had less access to health programs or } \\
\text { to healthy food choices, work schedules } \\
\text { caused meals to be hurried, and food } \\
\text { brought for potlucks and employee } \\
\text { appreciation did not provide healthy } \\
\text { choices. }\end{array}$ \\
\hline Focus groups 2 & $\begin{array}{l}\text { Patient care technicians, administrative } \\
\text { assistants, housekeepers, food service } \\
\text { workers, patient transport workers } \\
N=4 \text { groups; } 13 \text { individuals }\end{array}$ & $\begin{array}{l}\text { Feasibility and acceptability of } \\
\text { communication channels; current eating } \\
\text { and physical activity habits at work, } \\
\text { preliminary message testing }\end{array}$ & $\begin{array}{l}\text { Text messaging feasible and preferred. } \\
\text { Most people purchased food from the } \\
\text { hospital cafeteria and/or ate free food } \\
\text { brought in by others. Most had physically } \\
\text { demanding jobs and did not seek out } \\
\text { additional activity during break time. } \\
\text { The original intended name of the } \\
\text { intervention received negative feedback. }\end{array}$ \\
\hline Focus groups 3 & $\begin{array}{l}\text { Food service workers, housekeepers, patient } \\
\text { care technicians, registration clerks, } \\
\text { schedulers } \\
N=3 \text { groups and } 2 \text { one-on-one interviews; } \\
24 \text { individuals }\end{array}$ & $\begin{array}{l}\text { Information to refine workplace goals and } \\
\text { feedback on methods and logistics of } \\
\text { delivering iOTA in a workplace setting; } \\
\text { feedback about physical activity } \\
\text { self-monitoring }\end{array}$ & $\begin{array}{l}\text { Refinement needed to goals and } \\
\text { message wording to enhance relevance } \\
\text { and understanding. }\end{array}$ \\
\hline
\end{tabular}

(Focus Groups 2), which included 13 individuals. The focus group topics included current usage of text messaging, workplace eating and physical activity behaviors, perceptions of the proposed intervention, and feedback on message content and wording (focus group discussion guide is available in the Additional file 1). Interviews were not recorded in order to protect potentially sensitive information. In addition, recording and transcription were not necessary since the purpose of the focus groups was to get feedback about the intervention components (e.g. message timing, message content, logistics) as well as to gather additional information to be used in creating goal domains specific to the workplace. Participant responses and notes captured during the discussions were reviewed by the research team and used to make decisions about intervention modifications. This supported the decisions for incorporation of SMS messaging as a communication channel to reach the target population.

During goal and message development, we conducted a third round (Focus Groups 3) of three focus groups ( $n=24)$ with hospital employees from workgroups similar to those to be targeted for recruitment in the intervention (focus group discussion guide available in the Additional file 1). We used an iterative process for designing goals and messages based on information gathered during focus groups to inform subsequent focus groups. Consequently, recording and transcription were not necessary and summaries of focus group discussions, rather than systematic analysis of transcripts, were presented to the research team. Meetings of the research team were interspersed between the focus groups so that the responses and notes captured during the groups could be discussed and used to modify the intervention. This was aimed to ensure the goals and messages were relevant and understandable to the new target population. Topics for Focus Groups 3 were: perceptions of proposed intervention methods, additional workplace eating and physical activity questions including use of physical activity trackers for self-monitoring, and discussion around the logistics and feasibility of delivering the intervention in a workplace setting.

\section{Results}

Table 1 includes a summary of the key findings from the formative work. Multiple modifiable barriers to improving workplace health promotion were identified from key informant interviews and Focus Groups 1. The barriers were 
primarily related to lack of engagement included 1) communication barriers (many workers were unaware of the wellness initiatives offered by their employer); 2) barriers to healthy eating and program participation (i.e., night shift workers had less access to health programs or to healthy food choices, work schedules caused meals to be hurried, and food brought for potlucks and employee appreciation did not provide healthy choices); and 3) the opinion of many workers that their work activities provided sufficient exercise, obviating the need for or making them too tired for leisure time physical activity. Content modifications, such as the tailoring of goals and messages and substituting goals and components, were made based on these findings.

WFY was the product of this formative work. This adapted intervention maintains the theoretical premise and evidence base underpinning BFBW, which includes the importance of social-cognitive and socio-ecological factors [59-66], goal setting, and self-monitoring [52, 67-69]. This was informed by the literature developed by the BFBW trial as well as other important trials such as the DPP. Modifications are organized according to the Stirman model in Table 2. Like BFBW, WFY is a multi-level intervention, but capitalizes on the worksite-based nature of the intervention. This novel aspect of the intervention allowed WFY to maintain much of the theoretical basis from BFBW, but remain feasible for the worksite setting and relevant to the target population. This was particularly informed by findings related to barriers to participation identified in the survey and communication barriers identified in Focus Groups 1. Thus, WFY, like BFBW, includes components at two levels, (1) a participatory workgroup-level intervention designed to impact the entire work group, and available to all, and (2) an individual-level intervention (interactive obesity treatment approach; iOTA), targeting only workgroup employees with obesity.

The workgroup-level component of WFY incorporates the important social and physical environmental factors considered in BFBW, but includes a natural network (co-workers) and environment (workplace) where support and environmental changes can occur (Table 2). This is targeted through a participatory approach using the Intervention Design and Analysis Scorecard (IDEAS) tool [70] and a Human Centered Design approach [71-75] to engage members of the work group in designing and implementing interventions to promote healthy eating and physical activity through changes to the work environment. The remainder of the modifications focus on the iOTA, and are organized according to the Stirman model (Fig. 1 and Table 2).

\section{Who made the decision to modify}

The first set of categorizations within the Stirman model concern who contributed to decisions regarding adaptation. The decisions on how to modify the intervention were ultimately made by the interdisciplinary research team. This team included a dietitian, a behaviorist/ psychologist with experience in weight loss studies/ interventions, a health communication expert, an internal medicine physician, and occupational health experts with experience working with the target population. A member of the BFBW research team (original intervention developers) was also on the WFY research team. As described above, however, this was informed by, and conducted iteratively with, feedback and input from the target population. In this case, the providers delivering the iOTA intervention (health coaches) were members of the research team, and so were also involved with making these modifications. Finally, an external technology partner was included to develop and program the technological aspects of the iOTA for the modified intervention. This team made modifications to the following components from the Stirman model: Content, Context, and Training, which are mapped onto the framework by Stirman et al. [57], and summarized in Table 2.

\section{Context modifications}

A number of changes were made in the Context of the intervention (i.e., modifications made to the way BFBW is delivered); Context modifications can be made to Population, Setting, Personnel, and/or Format. As described above, WFY was adapted to low-wage employees at healthcare worksites from an intervention meant for patients with hypertension recruited at community health centers. Despite this difference, both populations are racially diverse and low-income.

For Personnel and Format, the WFY intervention includes personal interaction and electronic, automated interaction, as was the case in BFBW; however, there are far fewer formal personal interactions. While BFBW included (1) 18 individual telephone calls with a community health worker; (2) 12 bi-monthly group support sessions; and (3) tailored social and environmental action planning, WFY includes quarterly meetings with a health coach. Based in large part on the findings from Focus Groups 2, WFY provides participants with information about resources available from their employer, replacing the strategies to increase use of community resources, which was part of BFBW. Additionally, in WFY, participants are nested in their workgroup as described above. While this may seem like a modification to the Content, rather than the Context, this decrease in frequency did not lead to deleting elements beyond those described below. This modification was made both for the purposes of scalability within the hospital employee setting as well as to meet the preferences of participants, who have busy, dynamic schedules, making frequent 
Table 2 Description of how BFBW was modified according to Stirman model

\begin{tabular}{|c|c|c|}
\hline Modification & BFBW & WFY \\
\hline \multicolumn{3}{|l|}{ Who made decision to modify? } \\
\hline Individual practitioner & & - \\
\hline Team & & - \\
\hline Administrator or supervisor & & - \\
\hline Researcher & & $\begin{array}{l}\text { Surveys, interviews, and focus groups with } \\
\text { the target population and supervisors }\end{array}$ \\
\hline Intervention Developer & & $\begin{array}{l}\text { A member of the BFBW development team } \\
\text { included on the WFY workgroup }\end{array}$ \\
\hline Coalition of Stakeholders & & - \\
\hline \multicolumn{3}{|l|}{ What was Modified } \\
\hline Content modification & & Y (described below) \\
\hline Context modification & & Y (described below) \\
\hline Training and Evaluation & Community health worker training & Health coach training \\
\hline \multicolumn{3}{|l|}{ Context modifications } \\
\hline Population & $\begin{array}{l}\text { Low-income and racially diverse clinic patients } \\
\text { with obesity and hypertension }\end{array}$ & $\begin{array}{l}\text { Low-income and racially diverse healthcare } \\
\text { workers with obesity }\end{array}$ \\
\hline Setting & Community health centers & Worksite \\
\hline Format & $\begin{array}{l}\text { Interactive Voice Recognition or website with } \\
\text { community health worker phone calls }\end{array}$ & SMS with health coach meetings \\
\hline Personnel & Physician and community health worker & Health coach \\
\hline \multicolumn{3}{|c|}{ Level of delivery for Content modifications } \\
\hline Individual participant & Participant selects behavioral goals & Participant selects behavioral goals \\
\hline Group & & - \\
\hline Individual practitioner & & - \\
\hline Clinic/unit & Community health center & - \\
\hline Organization & Community health center & $\begin{array}{l}\text { Work group within an academic hospital } \\
\text { system }\end{array}$ \\
\hline Network & & - \\
\hline \multicolumn{3}{|l|}{ Nature of the Content modification } \\
\hline 1-Tailoring/tweaking/refining & & $\begin{array}{l}\text { Goals were tailored to the new setting, } \\
\text { population, and mode of delivery }\end{array}$ \\
\hline $\begin{array}{l}\text { 2-Integrating the intervention } \\
\text { into another framework }\end{array}$ & & - \\
\hline $\begin{array}{l}\text { 3-Integrating another treatment } \\
\text { into the intervention }\end{array}$ & & - \\
\hline 4-Removing/skipping elements & & $\begin{array}{l}\text { Hypertension medication adherence } \\
\text { component was removed }\end{array}$ \\
\hline $\begin{array}{l}\text { 5-Lengthening/extending } \\
\text { (pacing/timing) }\end{array}$ & 24 months & 24 months \\
\hline $\begin{array}{l}\text { 6-Shortening/condensing } \\
\text { (pacing/timing) }\end{array}$ & 24 months & 24 months \\
\hline $\begin{array}{l}\text { 7-Adjusting the order of } \\
\text { intervention components }\end{array}$ & & - \\
\hline 8-Adding elements & & - \\
\hline $\begin{array}{l}\text { 9-Departing from the intervention } \\
\text { ("drift") }\end{array}$ & & - \\
\hline 10-Loosening structure & & - \\
\hline 11-Repeating components & & - \\
\hline
\end{tabular}


Table 2 Description of how BFBW was modified according to Stirman model (Continued)

\begin{tabular}{cll}
\hline Modification & BFBW & WFY \\
\hline 12- Substituting & 15 goals, 7 removed- based on updated & 11 goals added - based on updated \\
& scientific evidence and target population perspectives & scientific evidence and target population perspectives \\
& MyHealthRisk & Baseline survey to inform plan \\
Group support sessions & Workgroup level intervention \\
\hline
\end{tabular}

personal interactions challenging, as identified in Focus Groups 1 and 2.

Also a part of Context in the Stirman model, Format is defined as changes made to the Format or channel of delivery. For several reasons including the findings from the formative work and Focus Groups 2, which identified high rates of SMS texting, but lower rates of access to smartphone apps in the context of the current intervention, WFY is delivered by Short Message Services (SMS) text instead of Interactive Voice Recognition or a web interface as was the case for BFBW. Low-SES populations have high rates of texting use, and interactive texting works well for health message delivery and as a tool for self-monitoring and adherence to interventions in low-income populations [76-81]. In contrast to web-based approaches to providing self-monitoring and feedback, SMS text has the advantages of being easily accessible to all workers, low cost, and quickly viewed. As a self-monitoring tool, text messaging offers a "minimal advice, maximal-contact" program [78]. The asynchronous communication offered by texting is appealing to workers who cannot make personal phone calls while at work, and for those with irregular work hours. Additionally, focus groups (Focus Groups 2) with the target population identified SMS messaging as a feasible and preferred communication channel; most participants reported having a cell phone and text messaging capabilities, but only five of the 36 focus group participants had a smart phone, so preferred SMS messaging to a separate smart phone application (e.g., an iPhone or android app) or web-based application.

The texting program also offers more frequent automated contact, as WFY has fewer personal contacts than BFBW. The SMS intervention in WFY is programed to "touch" participants an average of 5 days per week. The SMS system prompts participants to report their weight and their progress on achieving their goals on a "check-in" day each week, and sends immediate, tailored feedback based on their responses. If a participant is reporting progress on their goal, the SMS system suggests a change to the participant's goal (i.e., increasing behavior frequency or changing to a different target behavior) in between health coaching sessions. Since an aim of BFBW and WFY was to be sustainable and practical, components that would add increased cost were carefully considered, therefore this automatic feedback was provided instead of individualized goal-progress feedback. In addition, the system sends weekly and monthly tips customized to the goals the participant selected.

\section{Content modifications}

The Stirman model includes 12 ways in which an intervention's Content can be modified; Table 2 outlines in which of these categories we made Content modifications and briefly summarizes the adaptation. While the electronic interactions in WFY occur through SMS, rather than Interactive Voice Recognition or a web interface (as was the case in BFBW), the self-monitoring (Content) was designed with the same key principles in mind: "(1) be easily utilized in a short period of time; (2) include clearly discernible targets; and (3) track easily recallable information" $[51,52]$. As with BFBW, the goals were designed to be concrete and to promote an energy deficit and adherence to the intervention protocol $[51,52]$. However, these goals were Tailored to the WFY population (Individual participant level) and setting (Organization level), and involved some Substitution. The modifications to the goals (described in Table 2 under Nature of the content modification: substituting) incorporated findings from Focus groups 1 and were refined by the subsequent rounds of focus groups, which presented members of the target population with potential messages, as well as updated scientific evidence, as determined by the interdisciplinary team described above.

Nineteen behavior-based weekly goals were developed for WFY, 8 of which were adapted from BFBW. During the WFY intervention, participants will choose three of these goals during personal health coaching interactions. This is one area in which the Content was modified in terms of Removing core components; in BFBW, participants had hypertension, and were therefore required to select a goal related to hypertension management. In WFY, hypertension was not part of the inclusion criteria or intervention. The interdisciplinary team developed at least 15 tips for each of the 19 goals, which aimed to build self-efficacy, provide motivation, and deliver strategies to support behavior change. Where the team had concerns regarding the fit or comprehension of the tip content or wording, sample language was presented to potential participants for refinement and feedback. To facilitate self-monitoring, participants in both interventions were provided a device for physical activity 
monitoring (BFBW: pedometer; WFY: Fitbit). The other departure from BFBW was not including "MyHealthRisk", which is a web-based health risk assessment [82]. Instead, WFY included a baseline survey assessing risk behaviors, which was used to develop a personalized plan; participants receive a report based on their survey responses to review at their first coaching session.

\section{Discussion}

We modified the evidence-based weight and hypertension BFBW intervention to provide a scalable weight loss intervention in the context of a worksite setting with low-wage employees who did not necessarily have hypertension. This process led to an intervention that should be able to be sustainably implemented in workplace settings and also promotes healthy weight behaviors in low-SES worker populations. To allow comparison of study results and to inform future intervention efforts, it is important to formally map the modifications made to this intervention for the new setting and population [54]. While considerable attention has been paid to cultural adaptation, adaptation for implementation has not been well documented [55-57]. Although intervention adaptation is common, it is uncommon to describe the process and theoretical underpinning. Mapping such changes onto an adaptation framework [56] contributes to the growing implementation science literature [53, 54]. This adaptation process fits with other concepts guiding intervention design, including methods such as Intervention Mapping [83], which has been used within worksite health promotion [84-86] to improve intervention fit $[87,88]$.

Relations of worksite factors with obesity and chronic diseases such as diabetes have been seen elsewhere in the literature $[13,89]$. .The employee preferences identified in the current study and incorporated into the intervention adaptation have been identified in other employee populations [90, 91]. Factors identified in the formative work for the current adaptation process such as long work hours and hostile work environments have been found to be associated with obesity [13] and diabetes [89], highlighting the importance of incorporating these as intervention targets in an adapted intervention [91].

This study has limitations worth noting. For this study, we followed Chambers and Norton's guidance and applied the model by Stirman et al. [54, 57] However, there are several models for adaptation available [88, 92, 93], and the results obtained might have been different were another model selected. Regardless of the model used, we believe formally documenting the steps required for adaptation leads to more reproducible science and improved interventions. While we employed a framework to systematically document how BFBW was adapted to WFY with the aim of enhancing the generalizability of this experience, the study was conducted within only one hospital system in one city in the United States. Therefore, while the approach is likely to be generalizable, the findings from the resulting WFY intervention may not be [54].

The WFY intervention is currently being tested in a large group-randomized trial. As described above, the individual-level intervention is nested within a workgroup-level intervention in which employees participate for 2 years. Employees with obesity in the workgroup are eligible for the individual-level intervention. Survey measures and height and weight are measured at baseline and (all but height) at 6-month, 12-month, and 24-month follow-up. The primary outcome is weight; secondary outcome measures include dietary and physical activity behaviors as well as work satisfaction. In total, 22 workgroups (11 intervention and 11 control) will be enrolled, and approximately 308 participants with obesity (of 990 total) are expected to participate in the individual-level intervention.

\section{Conclusions}

Attention to how and why an evidence-based intervention is adapted for a new population and setting can inform others seeking to modify evidence-based weight management or other health interventions. This has particular relevance if the adapted intervention is found to be effective. WFY is designed to be scalable and relatively inexpensive, such that transparency in the adaptation process may make this intervention easier to translate to other work settings to reduce obesity and diabetes risk among low-SES workers, a group with a higher prevalence of these conditions.

\section{Additional file}

Additional file 1: Data collection tool. Focus group discussion guide. (DOCX $30 \mathrm{~kb})$

\section{Abbreviations}

BFBW: Be Fit Be Well; BMI: Body Mass Index; CDC: Centers for Disease Control; DASH: Dietary Approaches to Stop Hypertension; DPP: Diabetes Prevention Program; EMS: Emergency Medical Services; HWPP: Healthy Workplace Participatory Program; NIH: National Institutes of Health; SES: Socioeconomic status; SMS: Short Message Service; WFY: Working for You

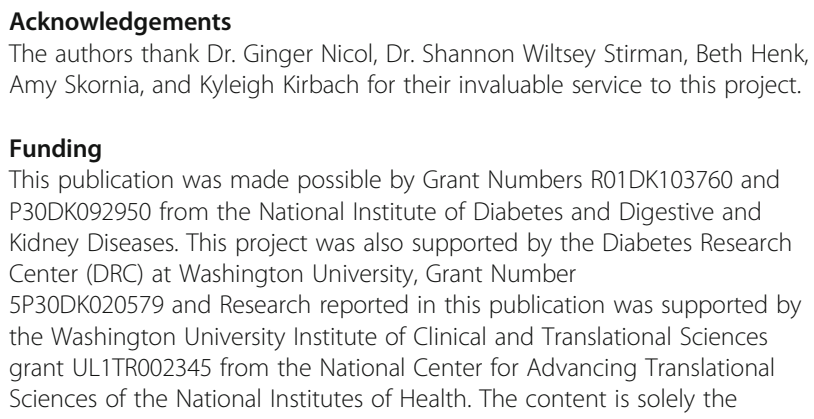


responsibility of the authors and does not necessarily represent the official view of the National Institutes of Health. These funding bodies had no role in the design of the study and collection, analysis or interpretation of data, or in writing the manuscript

\section{Availability of data and materials}

This study does not include a dataset, so a data availability statement is not applicable.

\section{Authors' contributions}

RGT participated in the adaptation process, applied the adaptation framework, and developed the manuscript. JRS managed the study and participated in the qualitative and quantitative methods data collection and intervention adaptation process. BK participated in the qualitative and quantitative methods data collection and intervention adaptation process. RIS, HD, and AMD participated in the intervention adaptation process. GAC was part of the original intervention team and assisted with the intervention adaptation process. BAE participated in the intervention adaptation process and designed and managed the study. All authors contributed to interpretation of the study and preparation of the manuscript and have read and approved the manuscript.

\section{Ethics approval and consent to participate}

Informed consent was obtained verbally for all participants, as data collection did not include identifiable information. This study was approved by the Human Research Protection Office at Washington University in St. Louis (\#201505131).

\section{Consent for publication}

Not applicable.

\section{Competing interests}

The authors declare that they have no competing interests.

\section{Publisher's Note}

Springer Nature remains neutral with regard to jurisdictional claims in published maps and institutional affiliations.

\section{Author details}

${ }^{1}$ Prevention Research Center in St. Louis, The Brown School, Washington University in St. Louis, 1 Brookings Dr, St. Louis, MO 63130, USA. ${ }^{2}$ Division of General Medical Sciences, Department of Medicine, Washington University School of Medicine, 4523 Clayton Avenue, Campus Box 8005, St. Louis, MO 63110, USA. ${ }^{3}$ Center for Human Nutrition, Department of Medicine, Washington University School of Medicine, 4523 Clayton Avenue, Campus Box 8083, St. Louis, MO 63110, USA. ${ }^{4}$ Division of Public Health Sciences and Alvin J. Siteman Cancer Center, Department of Surgery, Washington University School of Medicine, Washington University in St. Louis, 660 South Euclid Avenue, Campus Box 8100, St. Louis, MO 63110, USA.

\section{Received: 28 February 2018 Accepted: 1 November 2018}

\section{Published online: 16 November 2018}

\section{References}

1. Li Y, Pan A, Wang DD, Liu X, Dhana K, Franco OH, Kaptoge S, Di Angelantonio E, Stampfer M, Willett WC, et al. Impact of healthy lifestyle factors on life expectancies in the US population. Circulation. 2018. https:// doi.org/10.1161/CIRCULATIONAHA.117.032047.

2. Cancer and obesity. Overweight and obesity are associated with cancer [https://www.cdc.gov/vitalsigns/obesity-cancer/]. Accessed 7 Nov 2018.

3. Prevalence of Overweight, Obesity, and Extreme Obesity Among Adults Aged 20 and Over: United States, 1960-1962 Through 2013-2014 [https:/www.cdc. gov/nchs/data/hestat/obesity_adult_13_14/obesity_adult_13_14.pdf]. Accessed 7 Nov 2018.

4. G B D Obesity Collaborators. Health effects of overweight and obesity in 195 countries over 25 years. N Engl J Med. 2017;377:13-27

5. Finkelstein EA, Khavjou OA, Thompson H, Trogdon JG, Pan L, Sherry B, Dietz W. Obesity and severe obesity forecasts through 2030. Am J Prev Med. 2012;42(6):563-70.

6. Leung MY, Carlsson NP, Colditz GA, Chang SH. The burden of obesity on diabetes in the United States: medical expenditure panel survey, 2008 to 2012. Value Health. 2017;20(1):77-84.
7. Flegal KM, Carroll MD, Ogden CL, Curtin LR. Prevalence and trends in obesity among US adults, 1999-2008. JAMA. 2010;303(3):235-41.

8. Flegal KM, Kruszon-Moran D, Carroll MD, Fryar CD, Ogden CL. Trends in obesity among adults in the United States, 2005 to 2014. JAMA. 2016;315(21):2284-91.

9. Galobardes B, Morabia A, Bernstein MS. The differential effect of education and occupation on body mass and overweight in a sample of working people of the general population. Ann Epidemiol. 2000;10(8):532-7.

10. Sarlio-Lahteenkorva S, Silventoinen $\mathrm{K}$, Lahelma E. Relative weight and income at different levels of socioeconomic status. Am J Public Health. 2004;94(3):468-72.

11. Everson SA, Maty SC, Lynch JW, Kaplan GA. Epidemiologic evidence for the relation between socioeconomic status and depression, obesity, and diabetes. J Psychosom Res. 2002;53(4):891-5.

12. Mokdad AH, Ford ES, Bowman BA, Dietz WH, Vinicor F, Bales VS, Marks JS. Prevalence of obesity, diabetes, and obesity-related health risk factors, 2001. JAMA. 2003;289(1):76-9.

13. Luckhaupt SE, Cohen MA, Li J, Calvert GM. Prevalence of obesity among U.S. workers and associations with occupational factors. Am J Prev Med. 2014; 46(3):237-48.

14. Sun M, Feng W, Wang F, Li P, Li Z, Li M, Tse G, Vlaanderen J, Vermeulen R, Tse LA. Meta-analysis on shift work and risks of specific obesity types. Obes Rev. 2018;19(1):28-40.

15. Bennett GG, McNeill LH, Wolin KY, Duncan DT, Puleo E, Emmons KM. Safe to walk? Neighborhood safety and physical activity among public housing residents. PLoS Med. 2007;4(10):1599-606 discussion 1607.

16. Wolin KY, Bennett GG. Interrelations of socioeconomic position and occupational and leisure-time physical activity in the National Health and nutrition examination survey. J Phys Act Health. 2008;5(2):229-41.

17. Lovasi GS, Hutson MA, Guerra M, Neckerman KM. Built environments and obesity in disadvantaged populations. Epidemiol Rev. 2009;31:7-20.

18. Pearce J, Blakely T, Witten K, Bartie P. Neighborhood deprivation and access to fast-food retailing: a national study. Am J Prev Med. 2007;32(5):375-82.

19. Ross JS, Bradley EH, Busch SH. Use of health care services by lower-income and higher-income uninsured adults. JAMA. 2006;295(17):2027-36.

20. Agency for Healthcare Research and Quality. National Healthcare Quality Report. Rockville: US Dept Health and Human Services, Agency for Healthcare Research and Quality; 2010.

21. Cairns JM, Bambra C, Hillier-Brown FC, Moore HJ, Summerbell CD. Weighing up the evidence: a systematic review of the effectiveness of workplace interventions to tackle socio-economic inequalities in obesity. J Public Health (Oxf.). 2015;37(4):659-70.

22. Meng L, Wolff MB, Mattick KA, DeJoy DM, Wilson MG, Smith ML. Strategies for worksite health interventions to employees with elevated risk of chronic diseases. Saf Health Work. 2017;8(2):117-29.

23. Ma J, Yank V, Xiao L, Lavori PW, Wilson SR, Rosas LG, Stafford RS. Translating the diabetes prevention program lifestyle intervention for weight loss into primary care: a randomized trial. JAMA Intern Med. 2013;173(2):113-21.

24. NIOSH: Research Compendium: The NIOSH total worker health program: seminal research papers. Publication No. 2012-146. Washington, DC: U.S. Department of Health and Human Services, Public Health Service, Centers for Disease Control and Prevention, National Institute for Occupational Safety and Health, DHHS (NIOSH); 2012: 1-214.

25. National Institutes of Health, National Heart Lung and Blood Institute. Clinical guidelines on the identification, evaluation, and treatment of overweight and obesity in adults: the evidence report. Obes Res. 1998; 6(supplement 2):S51-\$209.

26. Anderson LM, Quinn TA, Glanz K, Ramirez G, Kahwati LC, Johnson DB, Buchanan $L R$, Archer WR, Chattopadhyay S, Kalra GP, et al. The effectiveness of worksite nutrition and physical activity interventions for controlling employee overweight and obesity: a systematic review. Am J Prev Med. 2009;37(4):340-57.

27. US Preventive Services Task Force. Screening for obesity in adults: recommendations and rationale. Ann Intern Med. 2003;139(11):930-2.

28. Special Committee on Health P. Healthy workforce/healthy economy: the role of health, productivity, and disability management in addressing the nation's health care crisis: why an emphasis on the health of the workforce is vital to the health of the economy. J Occup Environ Med. 2009;51(1):114.

29. Dodson EA, Lovegreen SL, Elliott MB, Haire-Joshu D, Brownson RC. Worksite policies and environments supporting physical activity in midwestern communities. Am J Health Promot. 2008;23(1):51-5.

30. You W, Almeida FA, Zoellner JM, Hill JL, Pinard CA, Allen KC, Glasgow RE, Linnan LA, Estabrooks PA. Who participates in internet-based worksite weight loss programs? BMC Public Health. 2011;11:709. 
31. Conn VS, Hafdahl AR, Cooper PS, Brown LM, Lusk SL. Meta-analysis of workplace physical activity interventions. Am J Prev Med. 2009;37(4):330-9.

32. Sorensen G, Stoddard A, Ockene JK, Hunt MK, Youngstrom R. Worker participation in an integrated health promotion/health protection program: results from the WellWorks project. Health Educ Q. 1996;23(2):191-203.

33. Heinen L, Darling $\mathrm{H}$. Addressing obesity in the workplace: the role of employers. Milbank Q. 2009;87(1):101-22.

34. Gabel JR, Whitmore H, Pickreign J, Ferguson CC, Jain A, K CS, Scherer H. Obesity and the workplace: current programs and attitudes among employers and employees. Health Aff (Millwood). 2009;28(1):46-56.

35. Morris WR, Conrad KM, Marcantonio RJ, Marks BA, Ribisl KM. Do blue-collar workers perceive the worksite health climate differently than white-collar workers? Am J Health Promot. 1999;13(6):319-24.

36. Conrad P. Wellness in the work place: potentials and pitfalls of work-site health promotion. Milbank Q. 1987;65(2):255-75.

37. Glasgow R, McCaul K, Fisher K. Participation in worksite health promotion: a critique of the literature and recommendations for future practice. Health Ed Q. 1993;20(3):391-408.

38. Healthy People 2020 [http://www.healthypeople.gov/2020/default.aspx]. Accessed 7 Nov 2018.

39. Gebhardt $\mathrm{DL}$, Crump C. Employee fitness and wellness programs in the workplace. Am Psychol. 1990;45(2):262-72.

40. Linnan L, Tate DF, Harrington CB, Brooks-Russell A, Finkelstein E, Bangdiwala S, Birken B, Britt A. Organizational-and employee-level recruitment into a worksite-based weight loss study. Clin Trials. 2012;9(2):215-25.

41. Baron SL, Beard S, Davis LK, Delp L, Forst L, Kidd-Taylor A, Liebman AK, Linnan $L$, Punnett $L$, Welch LS. Promoting integrated approaches to reducing health inequities among low-income workers: applying a social ecological framework. Am J Ind Med. 2014;57(5):539-56.

42. Linnan LA, Fava JL, Thompson B, Emmons K, Basen-Engquist K, Probart C, Hunt MK, Heimendinger J. Measuring participatory strategies: instrument development for worksite populations. Health Educ Res. 1999;14(3):371-86

43. Alexy B. Workplace health promotion and the blue collar worker. AAOHN J. 1990;38(1):12-6.

44. Barbeau EM, Li Y, Calderon P, Hartman C, Quinn M, Markkanen P, Roelofs C, Frazier $\mathrm{L}$, Levenstein $\mathrm{C}$. Results of a union-based smoking cessation intervention for apprentice iron workers (United States). Cancer Causes Control. 2006;17(1):53-61.

45. Champagne N, Abreu M, Nobrega S. Obesity/overweight and the role of working conditions: a qualitative, participatory investigation, 2012. In: Center of the promotion for health in the New England workplace; 2012. p. 1-30.

46. Nobrega S, Champagne N, Abreu M, Goldstein-Gelb M, Montano M, Lopez I, Arevalo J, Bruce S, Punnett L. Obesity/overweight and the role of working conditions: a qualitative, participatory investigation. Health Promot Pract. 2016;17(1):127-36.

47. Linnan LA, Sorensen G, Colditz G, Klar DN, Emmons KM. Using theory to understand the multiple determinants of low participation in worksite health promotion programs. Health Educ Behav. 2001;28(5):591-607.

48. Strickland JR, Eyer AA, Purnell JQ, Kinghorn AM, Herrick C, Evanoff BA Enhancing workplace wellness efforts to reduce obesity: a qualitative study of low-wage workers. Prev Chronic Dis. 2015;12:E67.

49. Strickland JR, Pizzorno G, Kinghorn AM, Evanoff BA. Worksite influences on obesogenic behaviors in low-wage workers in St Louis, Missouri, 2013-2014. Prev Chronic Dis. 2015;12:E66.

50. Glasgow RE, Gaglio B, Bennett G, Jerome GJ, Yeh HC, Sarwer DB, Appel L, Colditz G, Wadden TA, Wells B. Applying the PRECIS criteria to describe three effectiveness trials of weight loss in obese patients with comorbid conditions. Health Serv Res. 2012;47(3pt1):1051-67.

51. Bennett GG, Warner ET, Glasgow RE, Askew S, Goldman J, Ritzwoller DP, Emmons KM, Rosner BA, Colditz GA, Be Fit BWSI. Obesity treatment for socioeconomically disadvantaged patients in primary care practice. Arch Intern Med. 2012;172(7):565-74.

52. Greaney ML, Quintiliani LM, Warner ET, King DK, Emmons KM, Colditz GA, Glasgow RE, Bennett GG. Weight management among patients at community health centers: the "be fit, be well" study. Obes Weight Manage. 2009;5(5):222-8

53. Chambers DA, Glasgow RE, Stange KC. The dynamic sustainability framework: addressing the paradox of sustainment amid ongoing change. Implement Sci. 2013:8:117.

54. Chambers DA, Norton WE. The Adaptome: advancing the science of intervention adaptation. Am J Prev Med. 2016;51(4 Suppl 2):S124-31.
55. Baumann AA, Cabassa LJ, Wiltsey Stirman S. Adaptation in dissemination and implementation science. In: Brownson R, Colditz G, Proctor $E$, editors. Dissemination and implementation research in health: translating science to practice. 2nd ed. New York: Oxford University Press; 2018.

56. Stirman SW, Kimberly J, Cook N, Calloway A, Castro F, Charns M. The sustainability of new programs and innovations: a review of the empirical literature and recommendations for future research. Implement Sci. 2012;7(1):17.

57. Stirman SW, Miller CJ, Toder K, Calloway A. Development of a framework and coding system for modifications and adaptations of evidence-based interventions. Implement Sci. 2013;8:65.

58. Padgett DK. Qualitative methods in social work research. 2nd ed. Thousand Oaks: Sage Publications; 2008.

59. Bandura A, editor. Self-efficacy: the exercise of control. New York: W.H. Freeman and Co.; 1997.

60. Emmons KM. Behavioral and social science contributions to the health of adults in the United States. In: Smedley BD, Syme SL, editors. Promoting health: intervention strategies from social and behavioral research. Washington, DC: National Academy Press; 2000. p. 254-321.

61. Glasgow RE. A practical model of diabetes management and education. Diabetes Care. 1995:18(1):117-26.

62. Sallis J, Owen N. Ecological models of health behavior. In: Glanz K, Rimer BK, Viswanath K, editors. Health behavior: Theory, research, and practice. 5th ed. San Francisco: Jossey-Bass; 2015. p. 43-64.

63. Stokols D. Establishing and maintaining healthy environments: toward a social ecology of health promotion. Am Psychol. 1992;47(1):6-22.

64. Bronfenbrenner $U$. The ecology of cognitive development: Research models and fugitive findings. In: Wozniak RH, Fischer KW, editors. Development in context: Acting and thinking in specific environments. Hillsdale: Lawrence Erlbaum Associates, Publishers; 1993. p. 3-44.

65. Bronfenbrenner U. The ecology of human development: experiments by design and nature. Cambridge: Harvard University Press; 1979.

66. Bronfenbrenner U. Ecological systems theory. In: Vasta R, editor. Six theories of child development: revised formulations and current issues. London and Philadelphia: Jessica Kingsley Publishers; 1992. p. 187-249.

67. Bennett GG, Herring SJ, Puleo E, Stein EK, Emmons KM, Gillman MW. Webbased weight loss in primary care: a randomized controlled trial. Obesity (Silver Spring). 2010;18(2):308-13.

68. Sorensen G, Emmons K, Hunt MK, Barbeau E, Goldman R, Peterson K, Kuntz K, Stoddard A, Berkman L. Model for incorporating social context in health behavior interventions: applications for cancer prevention for working-class, multiethnic populations. Prev Med. 2003;37(3):188-97.

69. Knowler WC, Barrett-Connor E, Fowler SE, Hamman RF, Lachin JM, Walker EA, Nathan DM. Reduction in the incidence of type 2 diabetes with lifestyle intervention or metformin. N Engl J Med. 2002;346(6):393-403.

70. Robertson M, Henning R, Warren N, Nobrega S, Dove-Steinkamp M, Tibirica L, Bizarro A, CPH-NEW Research Team. The intervention design and analysis scorecard: a planning tool for participatory design of integrated health and safety interventions in the workplace. J Occup Environ Med. 2013;55(12 Suppl):S86-8.

71. Brown T. Design thinking. Harv Bus Rev. Harv Bus Rev. 2008;86(6):84-92.

72. Giacomin J. What is human Centred design? Des J. 2014;17(4):606-23.

73. Vechakul J, Shrimali BP, Sandhu JS. Human-centered design as an approach for place-based innovation in public health: a case study from Oakland, California. Matern Child HIth J. 2015;19(12):2552-9.

74. Design for Change [http://madpow.com/]. Accessed 7 Nov 2018.

75. IDEO.org [https://www.ideo.org/approach]. Accessed 7 Nov 2018.

76. Bennett GG, Steinberg DM, Stoute C, Lanpher M, Lane I, Askew S, Foley PB, Baskin ML. Electronic health (eHealth) interventions for weight management among racial/ethnic minority adults: a systematic review. Obes Rev. 2014; 15(Suppl 4):146-58.

77. Patrick K, Raab F, Adams MA, Dillon L, Zabinski M, Rock CL, Griswold WG, Norman GJ. A text message-based intervention for weight loss: randomized controlled trial. J Med Internet Res. 2009;11(1):e1.

78. Haapala I, Barengo NC, Biggs S, Surakka L, Manninen P. Weight loss by mobile phone: a 1-year effectiveness study. Public Health Nutr. 2009; 12(12):2382-91.

79. Pop-Eleches C, Thirumurthy H, Habyarimana JP, Zivin JG, Goldstein MP, de Walque D, MacKeen L, Haberer J, Kimaiyo S, Sidle J, et al. Mobile phone technologies improve adherence to antiretroviral treatment in a resourcelimited setting: a randomized controlled trial of text message reminders. AIDS. 2011;25(6):825-34 
80. Woolford SJ, Clark SJ, Strecher VJ, Resnicow K. Tailored mobile phone text messages as an adjunct to obesity treatment for adolescents. J Telemed Telecare. 2010;16(8):458-61.

81. Gerber BS, Stolley MR, Thompson AL, Sharp LK, Fitzgibbon ML. Mobile phone text messaging to promote healthy behaviors and weight loss maintenance: a feasibility study. Health Informatics J. 2009;15(1):17-25

82. Your Disease Risk: The source on prevention [https://siteman.wustl.edu/ prevention/ydr/. Accessed 7 Nov 2018.

83. Bartholomew LK, Parcel GS, Kok G, Gottlieb NH, Fernandez ME. Planning health promotion programs: an intervention mapping approach. 3rd ed. San Francisco: Jossey-Bass; 2011.

84. Kwak L, Kremers S, Werkman A, Visscher T, Van Baak M, Brug J. The NHFNRG in balance-project: the application of intervention mapping in the development, implementation and evaluation of weight gain prevention at the worksite. Obes Rev. 2006:8(4):347-61.

85. Strijk JE, Proper Kl, van der Beek AJ, van Mechelen W. A process evaluation of a worksite vitality intervention among ageing hospital workers. Int J Behav Nutr Phys Act. 2011;8:58.

86. Detaille SI, van der Gulden JW, Engels JA, Heerkens YF, van Dijk FJ. Using intervention mapping (IM) to develop a self-management programme for employees with a chronic disease in the Netherlands. BMC Public Health. 2010:10:353.

87. Morgan PJ, Collins CE, Plotnikoff RC, Cook AT, Berthon B, Mitchell S, Callister R. The impact of a workplace based weight loss program on work-related outcomes in overweight male shift workers. J Occup Environ Med. 2012:54(2):122-7.

88. Escoffery C, Lebow-Skelley E, Udelson H, Böing EA, Wood R, Fernandez ME, Mullen PD. A scoping study of frameworks for adapting public health evidence-based interventions. Transl Behav Med. 2018;16.https://doi.org/10 1093/tbm/ibx067.

89. Kivimaki M, Virtanen M, Kawachi I, Nyberg ST, Alfredsson L, Batty GD, Bjorner $J B$, Borritz M, Brunner EJ, Burr H, et al. Long working hours, socioeconomic status, and the risk of incident type 2 diabetes: a meta-analysis of published and unpublished data from 222120 individuals. Lancet Diabetes Endocrinol. 2015;3(1):27-34.

90. Hammerback K, Hannon PA, Harris JR, Clegg-Thorp C, Kohn M, Parrish A. Perspectives on workplace health promotion among employees in lowwage industries. Am J Health Promot. 2015;29(6):384-92.

91. Fitzgerald S, Geaney F, Kelly C, McHugh S, Perry IJ. Barriers to and facilitators of implementing complex workplace dietary interventions: process evaluation results of a cluster controlled trial. BMC Health Serv Res. 2016;16:139,

92. Aarons GA, Green AE, Palinkas LA, Self-Brown S, Whitaker DJ, Lutzker JR, Silovsky JF, Hecht DB, Chaffin MJ. Dynamic adaptation process to implement an evidence-based child maltreatment intervention. Implement Sci. 2012;7:32

93. Managing and Adapting Practice (MAP) [http://www.practicewise.com/ community/map]. Accessed 7 Nov 2018

Ready to submit your research? Choose BMC and benefit from:

- fast, convenient online submission

- thorough peer review by experienced researchers in your field

- rapid publication on acceptance

- support for research data, including large and complex data types

- gold Open Access which fosters wider collaboration and increased citations

- maximum visibility for your research: over $100 \mathrm{M}$ website views per year

At BMC, research is always in progress.

Learn more biomedcentral.com/submissions 